\title{
Improving the Scientific and Technological Innovation Activities
}

\author{
Feng Qian ${ }^{1}$ and Li Yang ${ }^{2, *}$ \\ ${ }^{1,2}$ College of Architecture \& Urban Planning, Tongji University, Key Laboratory of Ecology and Energy Saving Study of Dense \\ Habitat (Tongji University), Ministry of Education, Shanghai, P. R. China
}

${ }^{*}$ Corresponding author

\begin{abstract}
Scientific and technological innovation plays a more and more important role in the development of society and the progress of human civilization. Man is the main body of scientific and technological innovation activities, Essential qualities of people in science and technology innovation activities have higher requirements. In this article, aiming to promote the $S \& T$ capacity of our society, author conducts research from the perspective of required human qualities, and the research work of the key to improve S\&T capacity and provides some possible suggestions for improving qualities of innovative talents.
\end{abstract}

Keywords-scientific and technological; reaction capacity; innovative talents

\section{INTRODUCTION}

Science and technology (S\&T) have promoted the progress of human society and their rapid development has for opened up a broader space for social productivity development and human civilization. Many scholars have presented various descriptions about the essence of innovation ability. The innovation abilities in different views are considered as a comprehensive ability system although they are composed of various elements.

To obtain innovative skills in the field of engineering, S\&T talents should not only have the rich knowledge, broad vision, innovation awareness and creative thinking ability, but also have the ability to a large number of practical engineering backgrounds, the ability to solve practical engineering problems, manufacturing or engineering system operation and maintenance capabilities, product or project development and design capabilities, as well as the basic capabilities of project integration. In general, S\&T innovative talents should not only can find the problem, dare to ask questions, and have the ability to solve problems. Innovation ability in practice is another important feature of S\&T innovative talents.

In S\&T innovative activities, many unexpected things may happen due to the characteristic of unpredictability. Reaction capacity refers to the ability of people's taking measures to the environment when the ambient environment changes. This may be instinctive or the results of thinking and preparation after external stimuli. With the rapid development of S\&T, S\&T innovation activities would show an overall trend of fast growing [1]. S\&T innovative talents in the market environment should be sensitive to market demand and fast reaction capacity, namely, the ability to rapidly perceive the change of S\&T activities and the ability to conduct S\&T innovation.
S\&T innovation is a complicated process, so collaboration is needed to achieve an S\&T innovation. Team cooperation can often determine the achievements of a research project. With the fast change of modern S\&T, many subjects with the characteristics of complex, fine division and inter-discipline occur, which means that there will be more interdisciplinary research direction in future, so individual power is relatively small compared with the team cooperation. Thus, it is necessary to get the help of the collective wisdom and the power of team. Only by means of different disciplines, different fields and different levels of all members can S\&T innovative talents be possible to produce innovative results [2].

The concept of team cooperation is derived from the production process in the enterprise. It means that all the staff and administrative staff in an enterprise have to work as a community, which could make full use of the skills and knowledge of each member to reach their common goal. As Stephen P Robbins mentioned, collaboration is an organization that is combined by two or more interactive and independent individuals, for specific targets, according to certain rules. S\&T innovation team is an organic integration of innovation theory and team cooperation, so it can be seen as the application of innovation theory in the field of S\&T field. Specifically, under the background of modern production technology, in order to reach the common goal of research and development [3], S\&T innovation team is composed of outstanding talents and a certain number of S\&T individual, breaking the conventional limit of organization department. Thus, through the division of labor cooperation and resource sharing, S\&T can conduct basic research and applied research in a certain academic field around an innovation research direction.

In order to create a good S\&T innovation team, several principles should be followed.

1) Resource optimization principle. In constructing $S \& T$ innovation team, optimization innovation factors should be attached great importance. Therefore, in terms of optimization of overall goal, it is necessary to follow the principle of system, so as to coordinate the relationship of all departments or all members.

2) Reality principle. An S\&T innovation team should have a clear direction, task and purpose. According to their basic conditions and environmental conditions, it can be constructed in a planned way [4]. It should be highlighted that innovation team cannot be established in a simple way or in a single mode. 
At the same time, laws of S\&T development and talent growth should be respected.

3) Gradual principle. The construction of S\&T innovation team is a type of work based on practice, so it should be carried out step by step and cannot be realized in an action. Therefore, innovation team should be encouraged, promoted and guided to improve their team operational mechanism in practice. As a result, S\&T innovation, system innovation, mechanism innovation, management innovation can be achieved easier [5].

4) Define priority principle. S\&T innovation process is an integrated system, so only by the combination of all partners can they play their biggest role. But in terms of technological development, system integration should still follow the experience model of cumulative core technology.

\section{STRATEGIES FOR IMPROVING S\&T INNOVATION CAPACITY}

\section{A. Improving Innovative Quality: The Key to Improve S\&T Innovation Capacity}

It is obvious that innovation should be core content of S\&T innovation activities. In the traditional education, innovation education is rarely put on the agenda, namely, people rarely carry out production and life in an unconventional way [6]. Thus, innovation qualities of S\&T innovation talents become the key factors affecting the process of S\&T activities.

1) Creative personality: Curiosity is a kind of sensitive reaction to external stimulus, which plays an important role in $\mathrm{S} \& \mathrm{~T}$ innovation activities. It makes individual produce association, inspire people rich imagination, promote acute observation, enlighten people think independently, enhance creativity and then put forward some new questions. Raising a question is the beginning of solving a question [7]. The ancients used to want to fly on the moon, and now space shuttle is invented. It is clear that imagination can stimulate the appetite for innovation. Imagination is also a necessary factor that runs through the whole innovation process. In this process, S\&T innovative talents can combine all innovation achievements to contact and analyze all existing related resources, and then revise original association and imagination.

2) Creative thinking: Innovation activity is a kind of exploratory activity, which shows human beings' insights into the essence of objective things and change pattern of the development of objective things. This needs S\&T innovative talents put forward ideas and comments the predecessors did not. To do this, S\&T innovative talents should possess the quality of creative thinking. Divergent thinking, multidimensional thinking and radiation thinking are important parts of creative thinking, and all of them have the characteristics of flexibility, smoothness and originality. Adversity thinking is a question thinking method that is opposite to the common thinking way. This often brings unexpected success or a kind of novel and original ideas.

3) Scientific theory: In the process of researching a specific question, S\&T innovative talents should firstly generalize the specific issues based on scientific theory and philosophical principle, so as to determine the nature of their inherent connection [8]. Then on the basis of keen observation and rigorous scientific attitude, S\&T talents analyze these carefully and form a question, and that is the beginning of innovation and breakthrough.

\section{B. Strategies for Improving S\&T Innovative Talents Quality}

1) Creative training: It means a series of training that could improve the creative awareness, creative ability and perfect personality [9]. Creative training includes the training for improving creative thinking and training for enhancing creative imagination.

2) Continuous education: It is not only an important way to learn new knowledge, explore new thinking and start a new career, but also it is an important link to cultivate and improve the quality of S\&T innovative talents. The continuous education of S\&T innovative talents should be closely combined with actual situation and current S\&T development [10]. At the same time, based on the theme of new knowledge, new theory, new method and new technology, S\&T talents should adopt flexible and various education training methods to explore the means that could improve innovative awareness, innovative thinking, innovative spirit and practical ability, so that to totally achieve the goal of improve innovation quality.

3) Incentive mechanism: Motivation is closely related to the demand, and the demand should the prime power of all human behaviors. If there is no normal incentive mechanism, the innovative passion of S\&T talents will reduce, resulting in a lack of innovative awareness, innovative thinking and innovative spirit [11]. At present, the incentive mechanism should be established in the following aspects. Firstly, the intellectual property system should be improved to protect the lawful rights and interests of S\&T innovative talents. Secondly, a mechanism for efficient transformation of S\&T achievements should be established. Thirdly, fair and effective title appraisal and reward mechanism should be set up to strengthen the government incentive effect of S\&T innovation. Fourthly, innovative skilled S\&T workers from all walks of life should be stimulated [12]. In terms of treatment improvement of S\&T innovative S\&T personnel, it is necessary to improve the incentives of S\&T talents who have great contribution and to encourage them use their achievements, so as to improve their innovation enthusiasm.

4) Innovation investment: It is necessary to guide and encourage all kinds of stakeholders, especially large enterprise groups, to take the initiative to increase investment for the construction talent innovation quality, such as policies and measures, economic leverage and constraint mechanism. In addition, the fund management system should be established, so as to improve S\&T talent fund, innovation fund and risk funds for talent development, and eventually to form investment system for the construction of talent innovation quality in the whole society.

\section{CONCLUSIONS}

The arrival of information age has showed us the amazing power of science and technology, at the same time, technology is affecting the development of economy and society all over the world in an unprecedented grand imposing manner and an unimaginable speed. The advance of S\&T has brought human beings into an age of innovation. No innovation, no human 
civilization; No innovation, no the emergence and development of science and technology. Innovation is an extremely precious quality of civilization. In the era of knowledge economy, the development of knowledge shows two great trends: Breakthrough and Integration. Breakthrough can generate new knowledge and Integration can also generate, but both of them should be supported by creative capital, good moral quality, wide range of knowledge, innovative ability, personal reaction capacity, collaborative capability.

\section{ACKNOWLEDGMENT}

This work was financially supported by national science foundation of China 51178313/E0801 and 51378365.

\section{REFERENCES}

[1] J. Chen. The research on upgrading technological innovation capability of China's new energy storage. Central South University, 2013.

[2] E D. Bono. Teaching thinking. London: Temple Smith, 1976.

[3] Feng Qian, L.Yang, Research on the Sustainability of Urbanization in China, Applied Mechanics and Materials, Vol. 851, pp. 664-667, 2016.

[4] S. Wartick, L.,Philip L. C..The evolution of the corporate social performance model.Academy of management review, 1985,10 (4), 758769.

[5] Feng Qian, Li Yang, Research on the Sustainability of Urbanization in China, Applied Mechanics and Materials, Vol. 851, pp. 664-667, 2016.

[6] Li Yang, Feng Qian, Research on the Green Wind Environment Based on Numerical Simulation, Nature Environment and Pollution Technology, Vol. 15, No. 2 (June), 2016, PP767-772

[7] SSTC. Outline of technology innovation project. State Scientific and Technological Commission, 1996.

[8] L. K. Wang, X. L.Yin. Research on technology innovation ability and work performanceevaluation in Gansu Province. Beijing: China Economic Publishing House, 2010.

[9] Li Yang. Green building design: Building energy efficiency, Shanghai: Tongji University Press, 2016.

[10] W. Jiang. Research on technological innovation supporting system. Jilin University, China, 2011

[11] U. Lichtenthaler, Eckhard,L.. A Capability - Based Framework for Open Innovation: Complementing Absorptive Capacity. Journal of Management Studies, 2009, 46 (8), 1315-1338.

[12] B. Ganem. Strategies for innovation in multicomponent reaction design. Accounts of chemical research, 2009, 42 (3), 463-472. 